\title{
PODER JUDICIÁRIO: ÁRBITRO DOS CONFLITOS CONSTITUCIONAIS ENTRE ESTADOS E UNIÃO
}

\author{
Vanessa Elias de Oliveira
}

\section{Introdução ${ }^{1}$}

O federalismo tem sido cada vez mais estudado e discutido pela ciência política brasileira, sob os mais variados aspectos: fiscal, nos trabalhos sobre distribuição de recursos entre estados e guerra fiscal; eleitoral, no que tange à questão da representatividade dos estados nas Câmaras Alta e Baixa; social, atinente à produção de políticas sociais e variações nessas políticas nos diferentes governos, estados ou municípios. Esses são temas indubitavelmente relevantes, e suas análises têm trazido contribuições importantes tanto para o desenvolvimento da ciência política brasileira, quanto para o aprimoramento de políticas públicas no Brasil. No entanto, uma importante questão vem escapando aos olhos dos estudiosos do federalismo, em que pese a sua relevância para a compreensão do funcionamento das

\footnotetext{
${ }^{1}$ Agradeço a Cláudio Couto pela revisão cuidadosa e pelos pertinentes comentários, a Matthew Taylor, pelas excelentes críticas e sugestões, e a Paulo Baia e Emmanuel Oliveira Jr., pelas valiosas ajudas na análise dos dados. Agradeço também os questionamentos levantados pelo parecerista anônimo, instigantes e muito úteis para o aprimoramento do artigo.
} 
federações: o papel do Judiciário nestes sistemas, como um importante ator político no julgamento de litígios entre entes federados.

O presente artigo tem por objetivo trabalhar com a influência do Poder Judiciário no federalismo brasileiro, sob um aspecto específico: a forma pela qual o Supremo Tribunal Federal (STF) tem julgado as ações diretas de inconstitucionalidade (Adins) impetradas por estados contra a União, ou pela União contra os estados, no período que vai de 1988 a 2002. Ele demonstra empiricamente que as Adins impetradas pela União contra os estados têm maiores chances de "sucesso" do que aquelas impetradas pelos estados contra a União, o que pode ser o indício do desenvolvimento, no país, de um federalismo centralizador, representando a União um poderoso "Duque", ao invés de um federalismo estadualista, com seus vários "barões". ${ }^{2}$

Tais conflitos federativos, ou seja, conflitos diretamente 224 relacionados à busca, pelos entes federados, da limitação do poder dos demais, são frequentes em federações, e mais frequentes nelas do que nos estados unitários. Conforme lembrou Stepan (1999), ao analisar as razões pelas quais as federações democráticas são restritivas do poder central, nesses sistemas os diferentes níveis de governo (federal, estadual e, no caso brasileiro, municipal) dão pesos e investem esforços variados nas áreas passíveis de políticas públicas - saúde, educação, meio ambiente etc., gerando maiores conflitos de interesse, menos consenso e, portanto, maiores chances de questionamentos judiciais das ações governamentais. Nas palavras do autor,

“os limites do que é por consenso uma área de interesse do governo de uma unidade territorial, ou de preocupação do

\footnotetext{
${ }^{2}$ Faço menção aqui ao trabalho de Abrucio (1998). Outros trabalhos também tratam dos governadores como os "grandes barões" da federação. Ver também Samuels e Mainwaring (2004).
} 
governo federal, estão em permanente fluxo. A adjudicação de limites é, portanto, mais essencial e mais difícil em um sistema federativo do que em um sistema unitário. Assim, outro importante ator político cuja competência legislativa não se deve à verificação periódica do conjunto de cidadãos da polis (demos), ou mesmo dos cidadãos das unidades territoriais da federação (demoi), os tribunais, geralmente desempenham um papel mais importante em um sistema federativo do que em um sistema unitário" (Stepan, 1999).

Sendo assim, o STF tem um papel primordial no federalismo brasileiro, julgando conflitos constitucionais entre entes federados, nos quais está em jogo a adjudicação de limites aos poderes da União, estados e municípios. Em resumo, as ações diretas de constitucionalidade (Adins) expressam não apenas os conflitos federativos em si, no que diz respeito aos temas questionados, mas também a relação de poder entre as esferas de governo envolvidas - no nosso caso - estados e União.

A questão constitucional em sistemas federativos é tão importante que Riker, um dos principais teóricos do federalismo, embora afirme que

"é difícil fugir à conclusão de que as particularidades do federalismo (ou seja, os detalhes constitucionais e administrativos) não fazem nenhuma diferença”, salienta que "os advogados, principalmente os constitucionalistas, têm um pouco mais de trabalho em uma federação do que em um sistema unitário; salvo isso, não há muita diferença [entre os sistemas]" (Riker, apud Stepan, 1999).

Isso significa que questões de ordem constitucional estão presentes e são de fato relevantes no processo de funcionamento dos sistemas federativos, e daí a importância de serem analisadas pela ciência política. 
Acrescenta-se ainda o fato de que, como demonstraremos adiante, parece haver uma tendência a favorecer o poder central, em detrimento dos poderes regionais, num cabo de guerra no qual a União é, em geral, a vencedora. Esse "cabo de guerra”, em jogo no Brasil e em outras federações, torna ainda mais relevante a necessidade de compreensão da relação de poder entre governos central e regionais nos sistemas federativos. Conforme asseverou Wheare, no seu clássico estudo sobre federalismo,

"parece-nos que, na maioria dos governos federativos, o apaziguamento de disputas acerca dos termos da divisão de poderes é confiado a um corpo vitalício, nomeado pelo governo central. O resultado é que as Supremas Cortes - ou equivalentes - têm sido acusadas, de tempos em tempos, de uma parcialidade indevida, em favor do governo central" (Wheare, 1953, p. 62).

O presente artigo lida com essa questão, procurando demonstrar que há uma tendência do Poder Judiciário em favorecer o Governo central, em detrimento dos governos estaduais, nas questões de ordem constitucional que chegam ao STF. Assim, conforme Souza (2002), em oposição ao que aponta parte da literatura brasileira (Abrucio, 1998; Abrucio e Costa, 1998), o governo federal não se tornou um "jogador menor" dentro do jogo federativo, marcado por uma centralização nos estados e nos governadores. Contrariamente, existe uma divisão de funções e de poder e, em alguns casos, como mostraremos a seguir, o governo federal ganha vantagem no jogo.

O trabalho está dividido em três partes: primeiramente, discutiremos o papel do Poder Judiciário nas federações, a partir da análise da literatura sobre o tema, tanto nacional (escassa) como internacional. Em seguida, analisaremos os dados atinentes à atuação do STF no julgamento das Adins 
impetradas por estados contra o governo federal, ou deste contra aqueles e, então, discutiremos o papel do Judiciário brasileiro no julgamento de conflitos federativos. Por fim, partiremos para as conclusões acerca da relação entre Judiciário e Federalismo no Brasil, apontando ainda alguns temas relacionados, que precisam ser mais explorados pela ciência política brasileira, com o intuito de avançarmos no entendimento sobre o federalismo no Brasil.

Vale salientar que existe uma vasta literatura, tanto internacional quanto nacional, sobre a atuação política do Judiciário, a chamada "judicialização da política". ${ }^{3}$ Embora relevante, inclusive para uma discussão sobre o papel do Judiciário nas federações, não iremos aqui abarcá-la, uma vez que o foco do trabalho não é entender se existe ou não, ou mesmo em que grau, um papel "político" do Judiciário. Tomamos como pressuposto o caráter político da atuação do Judiciário na resolução dos conflitos federativos entre estados e governo federal.

\section{0 papel do Poder Judiciário nas Federações}

Um dos temas centrais no que diz respeito ao funcionamento do federalismo, embora pouco trabalhado no Brasil, é o papel do Poder Judiciário como árbitro de conflito entre os níveis de governo. No Brasil, cujo sistema federativo se destaca por seu caráter trino (União, estados e municípios são entes federados), esse papel é ainda maior, dada a existência de um elevado número de atores envolvidos em possíveis conflitos federativos.

Um trabalho de referência sobre o funcionamento dos sistemas federativos é o de Wheare (1953), no qual ele trata das federações que possuem não apenas "constituições

\footnotetext{
${ }^{3} \mathrm{Na}$ literatura internacional, conferir, dentre outros, Cappelletti (1993), Tate e Vallinder (1995), Garapon (1999) e Shapiro (1981, 2002). Na literatura nacional, Castro (1997), Arantes (1997, 2005), Werneck Vianna (1999), Vieira (2002), Oliveira e Carvalho (2005) e Oliveira (2003, 2005).
} 
federativas", mas que também apresentam uma "prática federativa de governo" - distinção essa fundamental para o autor. Dentre os países que se enquadram nessa distinção e que serão analisados pelo autor estão os Estados Unidos, o Canadá, a Suíça e a Austrália. O trabalho salienta que embora existam muitos outros países federativos, esses são os países que, na prática, possuem as duas características centrais desses sistemas: independência e coordenação entre as esferas de governo. Ao focar-se nessas características, ele demonstra a sua principal preocupação com relação às federações, qual seja, o seu funcionamento.

Não há como tratar da questão do funcionamento das federações sem passar pelos conflitos federativos dela resultantes e, somado a isso, ao papel de árbitro desses conflitos exercido pelo Poder Judiciário. Esse papel varia imensamente de país para país, de acordo tanto com o poder que é dado ao Judiciário para exercer o seu papel de árbitro,

228 como com o desenho institucional adotado pelas federações, no que tange aos limites de ação das esferas de governo, o que pode alterar o grau de questionamento, colocado à disposição dessas esferas, acerca das ações adotadas pelas demais esferas que com elas se coordenam. Obinger, Castles e Leibfried (2005a) apresentam de forma clara as principais diferenças entre as cortes constitucionais (ou Supremas, dependendo do país) de seis federações:

\section{Quadro 1}

Corte constitucional em seis federações

\begin{tabular}{|c|c|c|c|c|c|c|}
\cline { 2 - 7 } \multicolumn{1}{c|}{} & Austrália & Áustria & Canadá & Alemanha & Suíça & EUA \\
\hline Nome & High Court & $\begin{array}{c}\text { Verfassungs- } \\
\text { geristshof }\end{array}$ & $\begin{array}{c}\text { Supreme } \\
\text { Court }\end{array}$ & $\begin{array}{c}\text { Bundesver- } \\
\text { fassungsgericht }\end{array}$ & Bundesgericht & $\begin{array}{c}\text { Supreme } \\
\text { Court }\end{array}$ \\
\hline Estabelecida & 1901 & 1920 & 1875 & 1949 & $1948 / 1874$ & 1789 \\
\hline $\begin{array}{c}\text { Número } \\
\text { de juízes }\end{array}$ & 7 & 14 & 9 & 16 & 30 & 9 \\
\hline
\end{tabular}




\begin{tabular}{|c|c|c|c|c|c|c|}
\hline $\begin{array}{c}\text { Recruta- } \\
\text { mento por }\end{array}$ & $\begin{array}{c}\text { "Governor- } \\
\text { General" }\end{array}$ & Presidente & $\begin{array}{c}\text { Primeiro } \\
\text { Ministro }\end{array}$ & Eleição & Eleição & Presidente \\
\hline $\begin{array}{c}\text { Influência } \\
\text { das unidades } \\
\text { federadas via }\end{array}$ & Consulta & $\begin{array}{c}\text { Bundesrat } \\
\text { (3 juízes) }\end{array}$ & Consulta & $\begin{array}{c}\text { Bundesrat } \\
\text { (8 juízes) }\end{array}$ & $\begin{array}{c}\text { Ständerat via } \\
\text { Bundes- } \\
\text { versammlung }\end{array}$ & Senado \\
\hline $\begin{array}{c}\text { Revisão } \\
\text { judicial }\end{array}$ & $\operatorname{Sim}$ & $\operatorname{Sim}$ & $\operatorname{Sim}$ & $\operatorname{Sim}$ & $\begin{array}{c}\text { Não } \\
\text { (legislação } \\
\text { federal) }\end{array}$ & Sim \\
\hline
\end{tabular}

Fonte: Obinger, Castles e Leibfried (2005).

A Suprema Corte do Canadá, cujos membros são apontados pelo Executivo, é a corte final de apelação de todas as leis nacionais e decide sobre as disputas sobre divisão de poderes entre os entes federados. Em um caso importante de 1937, a Suprema Corte canadense ampliou o papel das províncias, ao repassar a elas a responsabilidade pelo programa de Seguridade Social, até então sob tutela federal. A justificativa era a de que as políticas sociais entrariam no rol de poderes provinciais sobre "propriedade e direitos civis" e "questões de natureza local ou privada" (Banting, 2005, p. 93). Também na Austrália disputas federativas (limites dos poderes constitucionais da Commonwealth e dos estados) são decididas pela Alta Corte da Austrália.

Na Suíça, por outro lado, a última palavra sobre conflitos constitucionais nem sempre cabe ao Tribunal Federal. Este pode declarar leis cantonais inválidas, mas deve aceitar as leis federais como válidas. De acordo com Wheare (1953),

"Isso significa que, enquanto as cortes estão envolvidas, qualquer assertiva da legislatura federal que tenha o poder de legislar num determinado campo de disputa, irá prevalecer e ser aceita. Isso não significa, no entanto, que a legislatura federal tenha a última palavra numa disputa sobre a extensão dos seus poderes, contra os dos cantões, 
uma vez que ainda resta o poder, exercido pelos 30.000 cidadãos ou 8 cantões, de que qualquer lei aprovada pela legislatura federal deve ser submetida à aprovação popular pelo referendum. Assim, num caso de disputa, o eleitorado tem o poder, se ele optar por exercê-lo, de decidir quando uma lei do governo federal é ou não válida" (Wheare, 1953, p. 61).

Os únicos dois países (dos seis analisados acima) nos quais os juízes da corte constitucional não são nomeados, mas, sim, eleitos, são Alemanha e Suíça. Essa nos parece uma diferença importante no que se refere à parcialidade das Cortes no julgamento de questões federativas, e parece-nos razoável supor que a eleição de juízes produz maior autonomia para eles no julgamento destas questões, quando comparados com juízes nomeados por uma das partes do litígio - em geral, o governo federal. Todavia, somente 230 estudos comparativos podem medir o efeito dessa variável (eleição ou nomeação de juízes) sobre o resultado dos julgamentos de conflitos federativos.

Nos Estados Unidos ${ }^{4}$, sobre a qual há uma grande produção acadêmica acerca da atuação do Judiciário, a última palavra sobre questões constitucionais e de divisão de poderes cabe à Suprema Corte, cujos membros são apontados pelo chefe do Executivo, o Presidente, com a aprovação do Senado. Isso remonta à Convenção de 1787, já havendo a concordância sobre a necessidade de um "Supremo Tribunal”, federal, para efetuar a autoridade nacional e conter as diversidades estaduais. A Corte deveria ser a balança entre a Nação e os estados, protegendo os interesses legítimos de ambos. Nas palavras de Katz:

\footnotetext{
${ }^{4}$ Centraremos nossa atenção no caso norte-americano não por considerarmos que seja o mais próximo ao brasileiro, mas sim por ser aquele com maior produção bibliográfica na direção do enfoque aqui trabalhado.
} 
"Durante toda a história americana, a Suprema Corte tem sido uma importante instituição e tem servido para aumentar o poder do governo nacional, muitas vezes em detrimento ao dos estados" (2001, s.p.).

Neste cenário, a revisão judicial seria um mecanismo para proteger o governo nacional das tendências centrífugas do federalismo.

$\mathrm{O}$ autor divide a história da Suprema Corte em três períodos principais: (a) de 1803 a 1865, marcado pelos conflitos acerca da natureza da união que a Constituição americana havia criado; (b) de 1865 a 1937, caracterizado pela rápida expansão da industrialização e consequente problema de definição da relação entre o governo e a nova ordem industrial; (c) de 1954 a 1968, período marcado pelos desafios de justiça social, equidade e liberdade individual.

Analisando a atuação da Suprema Corte nestes períodos, Katz demonstra que, em todos eles, a atuação da Corte tendeu ao fortalecimento do governo nacional, e não à sua limitação, diante do poder dos estados. ${ }^{5}$ Com isso, o autor assevera que três grandes questões constitucionais ainda rondam o tema do federalismo, que são:

1. Existe alguma limitação constitucional ao governo federal, dada a expansão do poder deste?

2. Dada a larga autoridade do poder central, qual o papel deixado aos estados na regulamentação das esferas social e econômica de seus cidadãos?

3. Se a Suprema Corte tornar-se menos atenta e "agressiva" na proteção das liberdades e direitos civis, as Cortes estaduais cobrirão esta lacuna e estarão atentas à defesa das liberdades individuais?

\footnotetext{
${ }^{5}$ Peterson (1995) demonstra o especial aumento de poder do governo federal americano diante dos estados durante os anos Roosevelt, no processo de implementação do New Deal.
} 
Ainda que não apresente respostas às questões, levantando-as como questionamentos a serem esclarecidos por pesquisas empíricas, Katz conclui:

"Durante sua história, a Suprema Corte norte-americana tem sido uma força integrativa e nacionalizadora na vida americana. Desde a sua fundação, ela esteve mais do lado do governo nacional do que do dos estados. Este padrão continua atualmente. A dificuldade é que o atual desafio do federalismo não é o das forças centrífugas advindas da diversidade dos estados; é da centralização de poder em Washington. [...] Dada a centralidade da Suprema Corte americana na política deste país, não deve haver dúvida de que a Corte continuará a ter um papel de fiel da balança" (Katz, 2001, s.p. - grifos meus).

Considerando, portanto, as semelhanças existentes nas estruturas federativas norte-americana e brasileira, a pergunta que se segue é: podemos supor que o comportamento das Supremas Cortes desses dois países são semelhantes, no que tange às disputas federativas, ou seja, contendas entre estados ou de estados contra o governo federal e vice-versa? Embora os Estados Unidos sigam a tradição do direito consuetudinário, cuja regra principal é a importância da precedência, conforme lembrou-nos Tsebelis, ${ }^{6}$ ao passo que o Brasil segue a lógica do direito civil, segundo a qual "[...] os juízes interpretam as leis, mas não as fazem” (2009, p. 316), o autor chama a atenção para o fato de que, ainda que essa distinção seja importante para se analisar a atuação das Cortes Supremas, as análises mais recentes indicam uma convergência desses dois sistemas. $\mathrm{O}$ que importa, do ponto de vista dos atores com poder de

\footnotetext{
${ }^{6}$ De acordo com Tsebelis,"decisões tomadas por juízes anteriores em casos similares são compulsórias para um juiz. Consequentemente, os juízes criam a lei, assim como a aplicam e interpretam" (2009, p. 316).
} 
veto analisados, é a capacidade das Cortes Supremas de interferirem nos sistemas políticos, e não tanto os sistemas legais nacionais. Mas não entraremos aqui nesta discussão. Em que pese essa diferença, vejamos como se comporta o Judiciário brasileiro na resolução desses conflitos, observando dados empíricos sobre o julgamento pelo STF das Adins que a ele chegaram, entre 1988 e 2002, envolvendo estados e a União.

\section{Os conflitos entre estados e governo federal no Brasil}

O Supremo Tribunal Federal (STF), Corte Suprema brasileira, é composto por onze Ministros e exerce a função de "guardião da Constituição". Esta tarefa de velar pela Constituição tornou-se ainda mais central nas atribuições do STF quando se deu a criação, pela Constituição Federal de 1988, do Superior Tribunal de Justiça, que absorveu parte das atribuições anteriormente conferidas ao STF, reforçando dessa forma a sua função de controle constitucional das leis. ${ }^{7}$ A Constituição de 1988 não modificou a estrutura do Supremo; o que houve foi uma redefinição de suas competências no sistema político-institucional brasileiro. Paralelamente, a Constituição ampliou a possibilidade de postular ação direta de inconstitucionalidade junto ao STF (Oliveira, 2003).

As ações diretas de inconstitucionalidade são um instrumento de questionamento da constitucionalidade de atos governamentais. De acordo com o artigo 103 da Constituição de 1988, podem propor Adin (e ação declaratória de constitucionalidade) (a) o Presidente da República; (b) a Mesa do Senado Federal; (c) a Mesa da Câmara dos Deputados; (d) a Mesa da Assembleia Legislativa ou a Câmara Legislativa do Distrito Federal; (e) o Governador de Estado

\footnotetext{
${ }^{7}$ A criação do STJ retira do Supremo uma de suas funções originais, como órgão de cúpula do Judiciário federal, que é a defesa da lei e a uniformização da jurisprudência federal, conforme apontou Arantes (1997).
} 
ou do Distrito Federal; (f) o Procurador Geral da República; (g) o Conselho Federal da Ordem dos Advogados do Brasil; (h) partido político com representação no Congresso Nacional; (i) confederação sindical ou entidade de classe de âmbito nacional.

O conjunto de dados que vamos aqui analisar é formado por 305 Adins (ações diretas de inconstitucionalidade), impetradas no período de 1988 a 2002, e fazem parte de um banco de dados mais amplo, ${ }^{8}$ formado por 941 ações acerca de questões federativas, ou seja, ações que têm como requerentes e requeridos órgãos federais, estaduais ou municipais. Utilizamos as Adins como objeto de análise, pois são elas o instrumento judicial para averiguação da constitucionalidade dos atos dos governos estaduais e federal, permitindo-lhes questionar, via Adin, a extensão da atuação dos demais níveis de governo no que diz respeito ao poder de legislar.

234 As ações aqui analisadas são de três tipos: a) aquelas que têm como requerente o Procurador Geral da União, e como requeridos os governadores de estado ou as assembleias legislativas estaduais; b) ações que têm como requerentes os Governadores, e como requerido o Presidente da República, o Senado, o Congresso ou Ministro de Estado $;^{9}$ c) aquelas que têm como requerentes assembleias legislativas estaduais e como requerido o Presidente da República ou o Congresso Nacional. Como os dois últimos tipos se

\footnotetext{
${ }^{8}$ Os dados foram obtidos pela autora no site do STF (www.stf.gov.br) e organizados em um banco de dados de Adins referentes aos conflitos federativos.

${ }^{9}$ Aqui, "Senado" e "Congresso Nacional" são tratados como órgãos que compõem a União, como ente federado, ainda que composto por membros que representem os estados. Levando-se em consideração que representam os estados, mas sob o ponto de vista dos interesses da União, ou seja, dos vários estados que compõem a "federação", e não de cada membro em particular, podemos considerá-los instituições da União. As Assembleias Legislativas estaduais, por outro lado, representam os estados, e por isso podemos considerar, no caso das ações destas contra atos do Congresso Nacional, um "cabo de guerra" em que de um lado temos os estados e, de outro, a União.
} 
referem a ações de estados versus União, juntamos ambos em um único grupo, o que nos forneceu dois grandes blocos de ações: aquelas impetradas por estados (governadores ou assembleias) contra a União, e aquelas da União contra os estados. Lembramos, ainda, que excluímos duas ações em que figurava a esfera municipal: uma de um prefeito contra o Presidente da República e outra de um governador contra um prefeito.

Além disso, os dados foram classificados pelo dispositivo legal questionado; tais dispositivos aparecem descritos no banco de dados do STF e foram classificados aqui de acordo com o tema central ao qual se referem. Ao todo, são nove grandes temas de dispositivos legais questionados.

Vale salientar que há uma grande disparidade no número de ações impetradas pela União, em comparação com o número de ações dos estados: a União acionou praticamente quatro vezes mais o Poder Judiciário para questionar a constitucionalidade das leis estaduais do que os estados questionaram as leis federais. Esse fato demonstra que provavelmente os atos estaduais estão "avançando mais o sinal", em termos de desvios constitucionais, do que o governo federal. Em oposição, podemos supor também que a União não tem interferido repetidamente na autonomia das esferas subnacionais, respeitando de certa forma os limites do federalismo brasileiro, dado que o número de questionamentos judiciais contra a interferência federal, por parte dos estados, é muito menor do que os do governo federal contra aqueles.

\section{0 julgamento do pedido de liminar}

As Adins podem ou não entrar com o pedido de liminar, o qual tem urgência para ser votado e, quando deferido, suspende imediatamente, até o julgamento do mérito da ação, os atos governamentais que estão sendo questionados. Analisamos os dados das Adins por intermédio do teste de Qui- 
quadrado, o qual compara as frequências observadas com aquelas que seriam esperadas caso não houvesse relação entre as variáveis. Apresentamos na tabela o resíduo ajustado padronizado, que é uma medida estatística utilizada como parâmetro para avaliação das frequências observadas em cada célula da tabela, mostrando se estas frequências diferem daquelas esperadas não apenas ao acaso (quando maior ou menor do que 2).

Tabela 1

Resultado das liminares das

Adins impetradas, 1988-2002

\begin{tabular}{|c|c|c|c|c|c|}
\hline & & & \\
\hline & & & $\begin{array}{c}\text { Estados } \times \\
\text { União }\end{array}$ & $\begin{array}{l}\text { União } \times \\
\text { Estados }\end{array}$ & Total \\
\hline \multirow{9}{*}{$\begin{array}{l}\text { Resultado } \\
\text { da liminar }\end{array}$} & \multirow{3}{*}{$\begin{array}{c}\text { Não } \\
\text { prosperou }\end{array}$} & $n^{0}$ & 39 & 47 & 86 \\
\hline & & $\%$ & $68,4 \%$ & $22,6 \%$ & $32,5 \%$ \\
\hline & & $\begin{array}{l}\text { Resíduo } \\
\text { Ajustado }\end{array}$ & 6,5 & $-6,5$ & \\
\hline & \multirow{3}{*}{ Prosperou } & $n^{0}$ & 9 & 153 & 162 \\
\hline & & $\%$ & $15,8 \%$ & $73,6 \%$ & $61,1 \%$ \\
\hline & & $\begin{array}{l}\text { Resíduo } \\
\text { Ajustado }\end{array}$ & $-7,9$ & 7,9 & \\
\hline & \multirow{3}{*}{$\begin{array}{l}\text { Aguardando } \\
\text { julgamento }\end{array}$} & $n^{\circ}$ & 9 & 8 & 17 \\
\hline & & $\%$ & $15,8 \%$ & $3,8 \%$ & $6,4 \%$ \\
\hline & & $\begin{array}{l}\text { Resíduo } \\
\text { Ajustado }\end{array}$ & 3,3 & $-3,3$ & \\
\hline \multirow{2}{*}{\multicolumn{2}{|c|}{ Total* }} & $n^{\circ}$ & 57 & 208 & 265 \\
\hline & & $\%$ & $100,0 \%$ & $100,0 \%$ & $100,0 \%$ \\
\hline
\end{tabular}

* Excluídas 40 Adins que não entraram com pedido de liminar.

Pearson Chi-square: 63,3. Significância: $\mathrm{p}<.000$

Fonte: www.stf.gov.br. Elaboração da autora.

Com relação ao resultado da liminar das Adins, vemos que $68,4 \%$ das liminares requeridas pelos estados "não pros- 
peraram”, o que significa que já foram julgadas, mas não foram deferidas - no todo ou em parte. Somado a isso, as liminares que prosperaram correspondem a apenas $15,8 \%$, exatamente a mesma quantidade de liminares que se encontravam aguardando julgamento.

No caso das Adins impetradas pelo governo federal, um novo padrão se apresenta, comparado ao das Adins estaduais: $\mathbf{7 3 , 6 \%}$ conseguiram deferimento, no todo ou em parte. Isto significa que, em quase três quartos dos casos, se conseguiu, por intermédio do Judiciário, suspender os atos estaduais considerados inconstitucionais. Mesmo que algumas liminares tenham sido posteriormente cassadas, elas tiveram um efeito imediato sobre as ações estaduais, e, além disso, demonstram que o Judiciário teve grande eficácia no julgamento das liminares requeridas pelo governo Central.

Salientamos que não estamos analisando o resultado encontrado pelo pedido de liminar caso a caso, assim como não o faremos para o resultado do mérito, com o intuito de sentenciarmos se houve ou não um julgamento político das Adins. Uma análise do resultado do mérito pode trazer dados interessantes sobre o âmago das decisões acerca das ações impetradas pelos entes federados, embora se corra o risco de, nesse caso, prevalecerem julgamentos pessoais sobre o resultado da sentença judicial - se justo ou injusto, se politicamente parcial ou imparcial.

Embora os dados já deixem clara a diferença entre os resultados das Adins, de acordo com o impetrante, apresentamos as porcentagens dos resultados do pedido de liminar em um gráfico, tornando mais clara a comparação.

Vemos que existe uma proporção inversa entre o resultado das liminares da União e o dos estados: enquanto que no primeiro caso $73,6 \%$ prosperaram, e somente $22,6 \%$ não obtiveram "sucesso", no segundo caso, dos estados, $\mathbf{6 8 , 4 \%}$ não prosperaram e apenas $15,8 \%$ foram deferidas ou 
Figura 1

Comparação da distribuição dos resultados obtidos pelas liminares das Adins impetradas pelos estados e pela União, 1988-2002

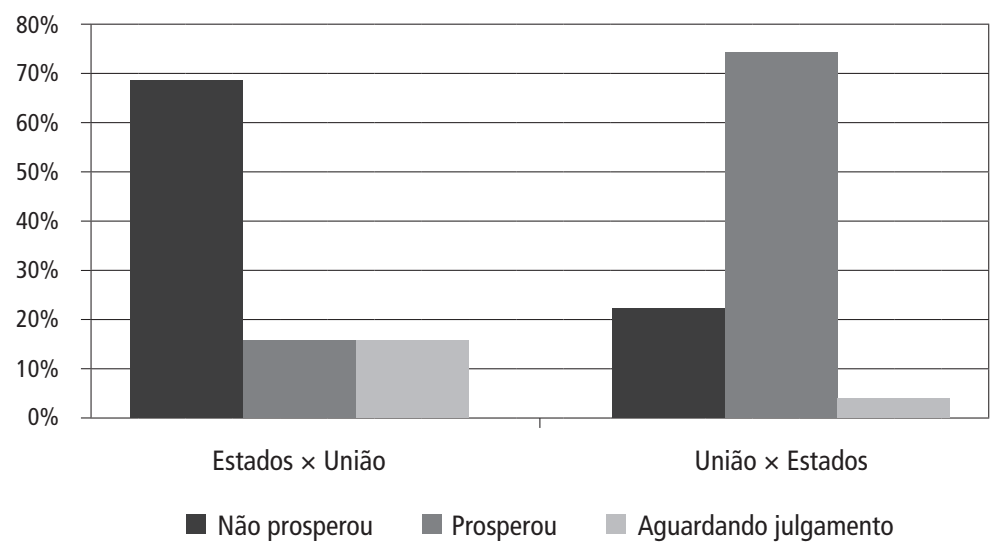

Fonte: www.stf.gov.br.

deferidas em parte. Os resíduos ajustados comprovam que os pedidos de liminar impetrados pela União têm maiores chances de prosperar $(7,9)$ do que os dos estados contra a União $(-7,9)$. Efetivamente, a União foi mais bem sucedida no cabo de guerra com os estados, em seus pedidos de liminar contra a inconstitucionalidade dos atos governamentais estaduais.

\section{O julgamento do mérito das Adins}

Analisando agora o resultado do mérito, temos que nenhuma ação impetrada por estados prosperou, ou seja, foi deferida. A maioria $(61,5 \%)$ não foi sequer apreciada, e encontrava-se aguardando julgamento. $O$ restante $(38,5 \%)$ já foi julgado e o mérito foi indeferido ou a ação foi extinta. 


\section{Tabela 2}

Resultado do mérito das Adins impetradas, 1988-2002

\begin{tabular}{|c|c|c|c|c|c|}
\hline & & & \multirow{3}{*}{$\begin{array}{c}\text { Estados } \times \\
\text { União } \\
25\end{array}$} & \multirow{3}{*}{$\begin{array}{c}\begin{array}{c}\text { União } \times \\
\text { Estados }\end{array} \\
58\end{array}$} & \multirow{3}{*}{$\begin{array}{c}\text { Total } \\
83\end{array}$} \\
\hline & & & & & \\
\hline \multirow{9}{*}{$\begin{array}{l}\text { Resultado } \\
\text { do mérito }\end{array}$} & \multirow{3}{*}{$\begin{array}{c}\text { Não } \\
\text { prosperou }\end{array}$} & $\mathrm{n}^{\circ}$ & & & \\
\hline & & $\%$ & $38.5 \%$ & $24,2 \%$ & $24,2 \%$ \\
\hline & & $\begin{array}{l}\text { Resíduo } \\
\text { Ajustado }\end{array}$ & 2,3 & $-2,3$ & \\
\hline & \multirow{3}{*}{ Prosperou } & $n^{\circ}$ & 0 & 54 & 54 \\
\hline & & $\%$ &, $0 \%$ & $22,5 \%$ & $17,7 \%$ \\
\hline & & $\begin{array}{l}\text { Resíduo } \\
\text { Ajustado }\end{array}$ & $-4,2$ & 4,2 & \\
\hline & \multirow{3}{*}{$\begin{array}{l}\text { Aguardando } \\
\text { julgamento }\end{array}$} & $\mathrm{n}^{\circ}$ & 40 & 128 & 168 \\
\hline & & $\%$ & $61,5 \%$ & 53,3 & $55,1 \%$ \\
\hline & & $\begin{array}{l}\text { Resíduo } \\
\text { Ajustado }\end{array}$ & 1,2 & $-1,2$ & \\
\hline \multirow{2}{*}{\multicolumn{2}{|c|}{ Total* }} & $n^{\circ}$ & 65 & 240 & 305 \\
\hline & & $\%$ & $100,0 \%$ & $100,0 \%$ & $100,0 \%$ \\
\hline
\end{tabular}

Pearson Chi-square: 19,1. Significância: $\mathrm{p}<.000$.

Fonte: www.stf.gov.br. Elaboração da autora.

É ao menos curioso o fato de que nenhuma das ações diretas de inconstitucionalidade impetradas pelos estados contra o governo federal tenha sido deferida, no todo ou em parte. Podemos supor que nenhuma delas realmente agredia a Constituição, o que justifica o seu indeferimento. Somente uma análise detalhada de cada uma das Adins poderá afirmar se havia ou não inconsistência no dispositivo legal questionado. Somado a isso, chama a atenção a quantidade de ações que foram indeferidas: um terço do total. Se excluíssemos da análise aquelas ações em andamento, teríamos que todas as Adins julgadas foram indeferidas, ainda que esse número possa vir a ser revertido com os julgamentos futuros. 
Com relação ao resultado do mérito das Adins, uma das características verificadas nas ações estaduais também foi encontrada para o caso federal: mais da metade das ações ainda se encontra aguardando o julgamento do mérito, o que demonstra que, embora o Judiciário tenha um bom nível de eficiência nas respostas ao pedido de liminares, o mesmo não se comprova no caso do resultado do mérito. Neste ponto, entramos na questão anteriormente levantada, de que talvez o Judiciário não queira intervir em ações de cunho político que envolvam o conflito entre as esferas de governo. E, sobretudo, o STF não quer interferir nas ações impetradas contra a União.

Por outro lado, ao passo que nenhuma ação estadual teve seu mérito julgado procedente, 22,5\% das Adins federais tiveram seu mérito julgado e prosperaram. Isto demonstra que também no caso do mérito das ações, o governo federal tem sido mais bem sucedido junto ao Judi-

240 ciário do que os governos estaduais. Somado a isso, a não apreciação das ações da União (53,3\%) é menor do que a porcentagem de ações dos estados que não foram apreciadas $(61,5 \%)$, ainda que a análise do resíduo ajustado demonstre que a diferença entre o esperado e o encontrado não é significativa. Ou seja, mesmo tendo que lidar com um número menor de ações dos estados, se comparado à União, o STF não as aprecia, o que parece indicar que há uma maior "disposição" do Supremo Tribunal em julgar umas às outras.

Retirando da análise as ações ainda inconclusas (aguardando julgamento), no caso das contendas federais contra os estados temos uma distribuição mais equilibrada: aproximadamente metade foi deferida e outra metade, indeferida. Embora apenas análises específicas possam nos explicar a razão exata para a disparidade no deferimento das ações, o fato é que tais números podem nos apontar uma tendência: o fato de nenhuma ação esta- 
Figura 2

Comparação do resultado do mérito das Adins

dos estados e da união, 1988-2002

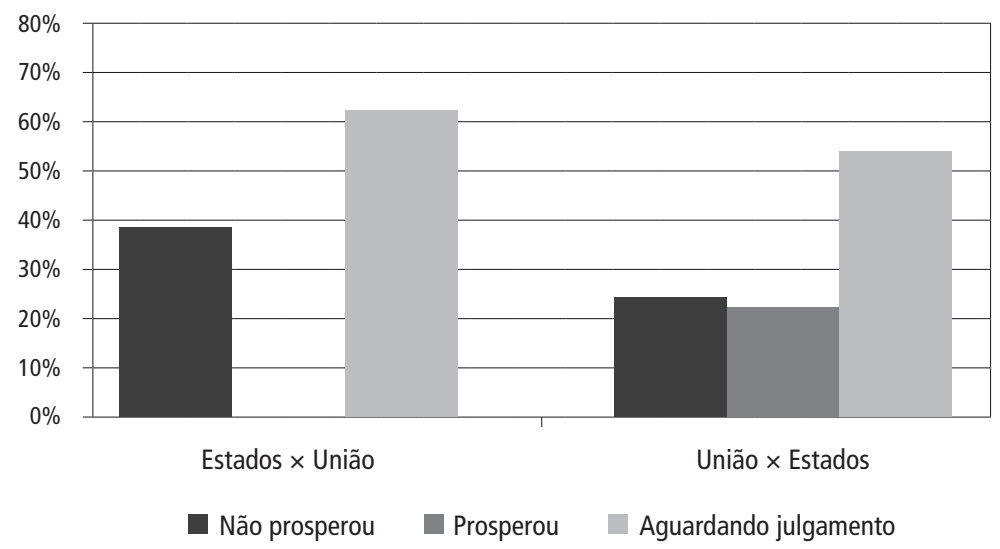

Fonte: www.stf.gov.br.

dual ter prosperado, em contendas contra a União, ao passo que metade das ações federais prosperou, contra os governos estaduais, pode significar um favorecimento do Poder Judiciário ao governo federal, produzindo algum grau de centralização do federalismo brasileiro? Essa é uma questão a ser aprofundada e, embora não seja aqui esgotada, os dados comparados ajudam a clarear o debate.

Assim como no caso das Adins dos estados, a análise dos resíduos ajustados nos mostra que as Adins impetradas pela União prosperam mais $(4,2)$, na apreciação de seus méritos pelo Judiciário, do que aquelas impetradas pelos estados $(-4,2)$. Esses dados comprovam que, para os casos analisados, a União se beneficiou mais da utilização de Adins como instrumento de questionamento da constitucionalidade dos atos dos governos subnacionais (e, portanto, do julgamento proferido pelo Judiciário) do que o contrário, tanto no que 
diz respeito à obtenção de liminar, quanto no julgamento do mérito das Adins propriamente ditos.

\section{Os dispositivos legais questionados}

Os dados acima parecem demonstrar uma tendência do Poder Judiciário brasileiro em favorecer a União, em detrimento dos estados, no julgamento de questões de constitucionalidade de ordem federativa. Todavia, uma questão merece ser levantada: o que faz os resultados serem diferentes? Uma das possíveis respostas encontra-se no tipo de questionamento que a União e os estados fazem ao Poder Judiciário. Não podemos nos aprofundar na "qualidade" das Adins, em termos de consistências no questionamento realizado, mas podemos atentar para o tema do questionamento. Assim, uma nova dúvida surge: é a União que é favorecida pelo Poder Judiciário, ou são os temas que ela questiona que são os "vitoriosos", nas contendas entre a União e os

242 estados? Enfim, o sucesso é da União, ou dos temas de dispositivos legais por ela questionados? Ao desagregarmos os dados por tipos de dispositivos legais questionados, conforme classificados no Quadro 1, novidades aparecem.

\section{Quadro 2}

Descrição das categorias legais questionadas nas Adins

\begin{tabular}{|c|l|}
\hline $\begin{array}{c}\text { Categorias dos Dispositivos } \\
\text { Legais Questionados }\end{array}$ & \multicolumn{1}{c|}{ Descrição das Categorias } \\
\hline 1. Administração Pública & \begin{tabular}{l} 
- Regulação das instituições públicas \\
e divisão de unidades político - \\
administrativas; \\
- Conflito de atribuição entre os três \\
Poderes; \\
- Crimes de responsabilidade do Estado. \\
\hline - Legislação sobre carreiras, remuneração, \\
organzação e aposentadoria do serviço \\
público; \\
\hline Regime jurídico dos servidores.
\end{tabular} \\
\hline
\end{tabular}




\begin{tabular}{|c|c|}
\hline 3. Política Social & $\begin{array}{l}\text { - Normas que tratam do sistema de } \\
\text { seguridade social não afetos ao } \\
\text { funcionalismo público; } \\
\text { - Legislação reguladora de acesso a } \\
\text { diferentes benefícios sociais. }\end{array}$ \\
\hline 4. Políticas Econômicas & $\begin{array}{l}\text { - Normas de regulação da economia } \\
\text { (políticas cambial, monetária e de preços); } \\
\text { - Propostas orçamentárias de estados e } \\
\text { municípios } \\
\text { - Reforma agrária e direito de greve. }\end{array}$ \\
\hline 5. Privatizações & $\begin{array}{l}\text { - Alienação de bens do Estado; } \\
\text { - Concessão de serviço público; }\end{array}$ \\
\hline $\begin{array}{l}\text { 6. Regulação Econômica do Setor } \\
\text { Público }\end{array}$ & $\begin{array}{l}\text { - Dívidas, débitos e precatórios judiciais do } \\
\text { Estado; } \\
\text { - Distribuição de verbas entre três Poderes. }\end{array}$ \\
\hline 7. Política Tributária & $\begin{array}{l}\text { - Normas que tratam da definição da base } \\
\text { - Le arrecadação e da alíquota de impostos } \\
\text { - Lei de Responsabilidade Fiscal. }\end{array}$ \\
\hline 8. Regulação da Sociedade Civil & $\begin{array}{l}\text { - Normas que ordenam as relações entre } \\
\text { particulares; } \\
\text { - Produção legislativa sobre o meio } \\
\text { ambiente e populações indígenas. }\end{array}$ \\
\hline 9. Competição Política & $\begin{array}{l}\text { - Normas relativas às eleições e aos } \\
\text { partidos políticos. }\end{array}$ \\
\hline 10. Relações de Trabalho & $\begin{array}{l}\text { - Normas que regulam o mundo do } \\
\text { trabalho - direitos do trabalhador e } \\
\text { organização sindical. }\end{array}$ \\
\hline
\end{tabular}

Fonte: Elaboração da autora.

Com base nessas categorias dos dispositivos legais questionados, primeiramente separamos os casos por tipo de impetrante da Adin, se estados (contra a União), ou União (contra os estados). Os resultados demonstram que as ações se dividem de maneira muito diferente, conforme o impetrante. 
Tabela 3

Dispositivos legais questionados, Adins, 1988-2002

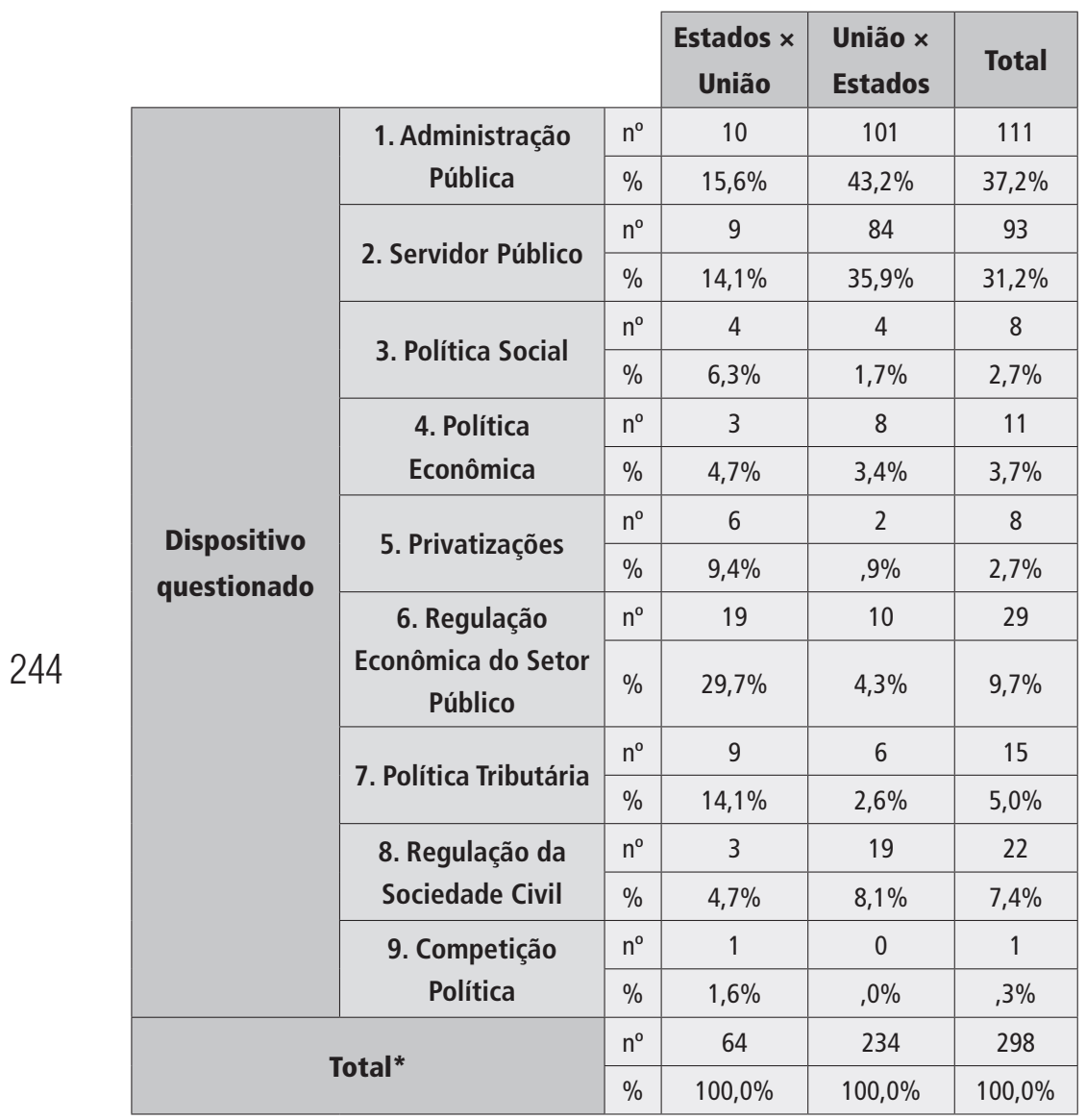

* Excluídas 6 Adins, que se encaixavam em mais de uma categoria, e 1 para a qual não havia informação.

Fonte: www.stf.gov.br. Elaboração da autora.

Observando as ações impetradas por estados, temos que elas se distribuem em quatro principais questionamentos: em primeiro lugar, a regulação econômica do setor público; em segundo lugar, os dispositivos acerca da administração 
pública; em terceiro, empatados, os dispositivos sobre o servidor público e de política tributária. Dentre os principais temas das disputas dos estados contra o governo federal no Brasil, podemos citar, como exemplos, ações que tratam do cálculo e do controle das liberações dos recursos do Fundo de Participação dos Estados e do Distrito Federal - FPE e do Fundo de Participação dos Municípios - FPM, ou ações atinentes a medidas provisórias acerca das diretrizes e incentivos fiscais para o desenvolvimento regional.

Quanto às ações impetradas pelo governo federal, percebemos que o "tipo de dispositivo legal questionado" é diferente daquele das ações do nível estadual. Nas federais, existem duas grandes áreas de concentração: administração pública e servidor público. Podemos citar como exemplos de questionamentos de constitucionalidade do governo federal contra os governos estaduais a criação de cargos públicos, a criação de municípios sem a realização de plebiscito ou, ainda, legislação sobre "pesca artesanal" nos estados.

A questão que surge, a partir dessa divisão dos temas questionados, é: dado que as ações da União se concentram em duas áreas, administração pública e servidor público, será que o fato de ela ser mais bem sucedida do que os estados não está relacionado com o sucesso que tais dispositivos têm junto ao Judiciário?

Pode até ser que não seja a União em si que tenha mais sucesso, mas, sim, os temas que ela propõe. O fato é que suas ações têm maiores chances de prosperar do que aquelas impetradas pelos estados. Todavia, para aprofundarmos essa análise, incluindo os temas dos dispositivos legais questionados, precisaríamos observar caso a caso, bem como as especificidades do questionamento, de forma que se captasse o âmago de cada ação, e a partir de então comparar a atuação do Judiciário em casos que sejam similares, impetrados por estados e pela União. É um trabalho minucioso, 
que pode trazer importantes descobertas sobre o padrão de atuação do Poder Judiciário em contendas federativas. Mais do que isso, considerando que nenhuma Adin dos estados teve seu mérito julgado como procedente, não poderíamos comparar, com base no banco de dados aqui utilizado, o sucesso das ações por temas, em relação ao seu impetrante. Somente trabalhos mais específicos, com análises mais aprofundadas de alguns casos, podem trazer avanços nesse campo de pesquisa.

\section{Conclusão}

Os dados acima analisados, embora deem apenas um impulso para discussões futuras acerca do papel do Poder Judiciário em sistemas federativos, em especial no federalismo brasileiro, trazem indícios de duas possíveis hipóteses, a serem aprofundadas.

Em primeiro lugar, dado o alto número de ações não

246 julgadas pelo STF (quase $60 \%$ do total), a questão que parece pertinente é: podemos dizer que o Judiciário está se eximindo de julgar os conflitos federativos e, portanto, não está cumprindo o papel de "freio e contrapeso" no cabo de guerra entre os entes federados no federalismo brasileiro? Talvez o alto número de Adins não julgadas não signifique uma escusa do Poder Judiciário de julgar os conflitos federativos, mas apenas demonstrem a fragilidade desse instrumento, como árbitro de contendas judiciais, para a resolução de questões federativas, ainda mais se consideramos a necessidade de respostas rápidas para casos de disputa de poder como, por exemplo, guerra fiscal entre estados com interferência do governo central.

Em segundo lugar, o Poder Judiciário brasileiro, ao prepor as Adins impetradas pelo governo federal, em comparação àquelas dos governos estaduais, estaria favorecendo o desenvolvimento de um federalismo centralizador, representando a União um poderoso "Duque", conforme apon- 
tamos anteriormente? O trabalho de Figueredo e Limongi (1999), dentre outros, mostrou que o Executivo federal conseguiu importantes vitórias no Legislativo, inclusive contrárias aos interesses dos estados, questionando a hipótese de que os governadores seriam os grandes "barões da federação" a partir de 1988. Talvez os dados acima apresentados apontem para o fato de que o governo federal venha sendo, também na arena judicial, o principal vencedor, embora isso não signifique que seja o único, sempre.

Uma justificativa possível, para a apontada propensão do Judiciário em atentar mais para os pedidos de revisão da constitucionalidade impetrados pelo governo federal do que àqueles dos governos estaduais, pode ser dada pela relação de proximidade entre o Supremo Tribunal e o Executivo federal, já que seus membros são nomeados por este. Madison (2003), no artigo 51 d'Os Artigos Federalistas, afirma que é sempre desejável haver uma separação de poderes como forma de garantir a liberdade e, para isso, dever-se-ia evitar que os membros de cada um dos três Poderes fossem nomeados por membros dos outros Poderes. Todavia, lembra o autor, o caso do Judiciário seria uma exceção, dada a necessidade de se garantir a excelência do profissional, e porque a garantia de permanência no cargo "destruiria" qualquer dependência de autoridade que pudesse haver.

Sobre tal potencial subordinação, Wheare (1953) afirmou que, embora haja certo grau de dependência das Supremas Cortes por ele analisadas (EUA, Canadá, Austrália e Suíça) ao Executivo, isso não produz, necessariamente, um mau governo. Da mesma forma, a independência do Poder Judiciário não produziria, a priori, um bom governo, podendo inclusive gerar, no extremo, uma tirania dos juízes. Bom ou mau, no governo, entretanto, são juízos de valor que dependem, ainda, de um conjunto de variáveis que não apenas a atuação judicial. Sendo assim, a questão 
central não é tanto se a "dependência” do Judiciário ao Executivo federal produz ou não um bom governo, no sentido mais amplo e idealizador do termo, mas se produz ou não distorções na divisão de poderes dos sistemas federativos, com o favorecimento do governo central, em detrimento dos governos estaduais.

Diante dessas essas questões, e analisando o julgamento das Adins dos governos estaduais e federal pelo STF, devemos nos perguntar até que ponto não estaria o Poder Judiciário brasileiro favorecendo certa centralização do sistema federativo brasileiro, tal como parece ocorrer na divisão de funções entre esferas de governo no que tange à elaboração de diretrizes de políticas sociais, conforme já aventado por Almeida (2005), como também na divisão de poderes legislativos mais abrangentes, sobre questões outras como, por exemplo, regulação econômica do setor público e política tributária, tornando os estados perdedo-

248 res reiterados no jogo do cabo de guerra federativo. Essa parece ser uma tendência no federalismo norte-americano, conforme apontamos, que talvez esteja se mostrando procedente também para o caso brasileiro. Enfim, esse é um tema atual e relevante, que merece ser aprofundado pelos estudos sobre o Judiciário e sobre o federalismo na ciência política brasileira, objetivando uma visão mais abrangente acerca do funcionamento do sistema federativo no Brasil, bem como sobre a chamada judicialização da política, avançando e indo além das questões já tratadas pela literatura. Os dados apresentados pretenderam apenas dar o pontapé inicial para essa compreensão, buscando aguçar a curiosidade dos pesquisadores envolvidos com estes dois temas.

\section{Vanessa Elias de Oliveira}

é professora de Ciência Política da Universidade Federal do $\mathrm{ABC}$ 


\section{Referências bibliográficas}

ABRUCIO, F. 1998. Os barões da federação: os governadores e a redemocratização brasileira. São Paulo: Hucitec/USP.

; COSTA, V. 1998. Reforma do Estado e o contexto federativo brasileiro. São Paulo: Konrad Adenauer Stiftung.

ALMEIDA, M. H. 2005. "Recentralizando a federação?”. Revista de Sociologia e Política, $\mathrm{n}^{\circ}$ 24, pp. 29-40, junho.

ARANTES, R. 1997. Judiciário e Política no Brasil. São Paulo: Idesp/Editora Sumaré/Fapesp: Educ.

. 2005. "Constitutionalism, the expansion of justice and the judicialization of politics in Brazil”. In: SIEDER, R.; SCHJOLDEN; L.; ANGELL, A. (org.). The judicialization of politics in Latin America. New York: Palgrave Macmillan.

BANTING, K. 2005. "Canada: Nation-building in a federal welfare state". In: OBINGER, H., LEIBFRIED, S.; CASTLES, F. (eds.). Federalism and the Welfare State: new world and European experiences. Cambridge University Press.

CAPPELLETTI, M. 1993. Juizes Legisladores? Porto Alegre: Sérgio Antônio Fabris Editor.

CASTRO, M. F. 1997. "O Supremo Tribunal Federal e a Judicialização da Política”. Revista Brasileira de Ciências Sociais, vol. 12, n 34, pp. 147-156.

FIGUEREDO, A. e LIMONGI, F. 1999. Executivo e Legislativo na Nova Ordem Constitucional. São Paulo: Editora FGV/Fapesp.

GARAPON, A. 1999. O juiz e a democracia: o guardião de promessas. Rio de Janeiro: Revan.

GIBSON, E. (ed.). 2004. Federalism and democracy in Latin America. Baltimore: The John Hopkins University Press.

HAMILTON, A.; MADISON, J.; JAY, J. 2003. The Federalist Papers. New York: Bantam Books.

KATZ, E. 2001. "The Supreme Court and the integration of American federalism", mimeo.

OBINGER, H., CASTLES, F. e LEIBFRIED, S. 2005a. "Federalism and the Welfare State". In: ; LEIBFRIED, S.; CASTLES, F. (eds.). Federalism and the Welfare State: new world and European experiences. Cambridge University Press.

; LEIBFRIED, S.; CASTLES, F. (eds.). 2005b. Federalism and the Welfare State: new world and European experiences. Cambridge University Press.

OLIVEIRA, V. 2003. O Poder Judiciário brasileiro após a constituição de 1988. Existe uma judicialização da política? Dissertação de mestrado defendida junto ao Departamento de Ciência Política da USP. 
OLIVEIRA, V. 2005. "Judiciário e privatizações no Brasil: existe uma judicialização da política?". Dados - Revista de Ciências Sociais, Rio de Janeiro, vol. $48, \mathrm{n}^{\circ} 3$.

OLIVEIRA, V.; CARVALHO, E. 2005. “A judicialização da política: um tema em aberto”. Política Hoje - Revista do Mestrado em Ciência Política da UFPE, vol.b1, $\mathrm{n}^{\circ} 15$.

PETERSON, P. 1995. The price of federalism. New York: The Twentieth Century Fund.

SAMUELS, D.; MAINWARING, S. 2004. "Strong Federalism, Constrains on Central Government, and Economic Reform in Brazil”. In: GIBSON, E. (ed.). Federalism and democracy in Latin America. Baltimore: The John Hopkins University Press.

SHAPIRO, M. 1981. Courts: a comparative and political analysis. Chicago University of Chicago Press. ; STONE SWEET, A. 2002. On law, politics, and judicialization. Oxford: Oxford University Press.

SIEDER, R.; SCHJOLDEN; L.; ANGELL, A. (org.). 2005. The judicialization of politics in Latin America. New York: Palgrave Macmillan.

SOUZA, C. 2002. "Brazil: The Prospects of a Center-Constraining Federation in a Fragmented Polity". Publius. Spring 2002, vol. 32, n. 2, 250 pp. 23-48.

STEPAN, A. 1999. "Para uma nova análise comparativa do federalismo e da democracia: federações que restringem ou ampliam o poder do Demos". Dados - Revista de Ciências Sociais, vol. 42, nº 2.

TATE, N.; VALLINDER, T. (eds.). 1995. The global expansion of judicial power. New York, New York University Press.

TSEBELIS, G. 2009. Atores com poder de veto. Como funcionam as instituições políticas. Rio de Janeiro: Ed. FGV.

VIEIRA, O. V. 2002. O Supremo Tribunal Federal: jurisprudência política. São Paulo: Malheiros.

WERNECK VIANNA, L. et al. 1999. A judicialização da política e das relações sociais no Brasil. Rio de Janeiro: Revan.

WHEARE, K. C. 1953. Federal Government. London: Oxford University Press. 